\title{
Mantle anisotropy across the southwestern boundary of the Ordos block, North China*
}

\author{
Yongcai Tang ${ }^{1}$ Yongshun John Chen ${ }^{1, \uparrow}$ Yuanyuan V. Fu ${ }^{1}$ \\ Haiyang Wang ${ }^{1}$ Shiyong Zhou ${ }^{1}$ Eric Sandvol ${ }^{2}$ \\ Jieyuan Ning ${ }^{1}$ Yongge Feng $^{1}$ and Mian Liu $^{2}$ \\ ${ }^{1}$ Department of Geophysics, School of Earth and Space Sciences, Peking University, Beijing 100871, China \\ ${ }^{2}$ Department of Geological Sciences, University of Missouri, Columbia, MO 65211, USA
}

\begin{abstract}
Located at the northeastern margin of the Tibetan plateau, the Ordos block is a stable tectonic unit in North China. With its active boundary fault zones, the Ordos block played an important role in the eastward extrusion mechanism of the Tibetan plateau. Peking University deployed a linear array of 15 portable broadband seismometers across the western Weihe graben during September 2005 to August 2006 and later a 2-D seismic array (Southwest Ordos Array) of 14 portable broadband seismometers during 2007-2008 at its southwestern boundary. Analyses of shear wave splitting of SKS and SKKS phases at these stations show that the fast directions trend $\sim 110^{\circ}$ with an average delay time of $0.9 \mathrm{~s}$ in the southwestern margin of the Ordos block. The agreement between the lithosphere deformation indicated by GPS data and Quaternary fault slip-rate observations and the mantle flow represented by shear wave splitting implies that accordant deformation patterns from lithosphere to asthenosphere in relation to the eastward extrusion of the Tibetan plateau could extend at least to $200 \mathrm{~km}$ depth. Spatial distribution of splitting polarization directions indicates that the mantle flow driven by the Tibetan plateau is blocked by the Ordos block and locally restricted in a narrow channel along the Qinling-Dabie fault zones between the Ordos block and Sichuan basin.
\end{abstract}

Key words: shear wave splitting; Weihe graben; Ordos; mantle anisotropy

CLC number: P315.2 Document code: A

\section{Introduction}

The northeastward expanding Tibetan plateau, driven by the continued Indo-Asian continental collision (Yin and Harrison, 2000), has encountered the North China craton at the southwestern side of the Ordos block. The Ordos block is a stable rigid continental block with Late Cenozoic active extensional boundaries but little deformation and seismicity in its interior (Figure 1). It is thought that this convergence between Tibet and Ordos has resulted in the development of the Liupanshan mountain belt and an eastward extrusion of crustal and upper mantle material between the stiff Ordos block and Sichuan basin (Tapponnier and Molnar, 1977; Zhang et

\footnotetext{
* Received 26 October 2010; accepted in revised form 18 November 2010; published 10 December 2010.

^ Corresponding author. e-mail: johnyc@pku.edu.cn

(C) The Seismological Society of China and Springer-Verlag Berlin Heidelberg 2010
}

al., 1998; Yin and Harrison, 2000). Both rifting of Weihe graben and reactivation of Qinling orogen have been interpreted to be the consequence of this process (Figure 1), but how Weihe graben and Qinling orogen accommodate the eastward extrusion of the Tibetan material is still in debate.

Seismological studies have been conducted around the Ordos block from many aspects, such as receiver functions (Chen et al., 2005; Tong et al., 2007; Tang et al., 2010), shear wave splitting (Huang et al., 2008), reflected and refracted seismic profiles (Yang et al., 2009). However, the crustal and mantle structures in this region remain largely unknown. In this study, we present the analyses of shear wave splitting at the southwestern margin of the Ordos block using teleseismic records at two Peking University arrays, reflecting the mantle flow from the collision of Tibet and Ordos to the extensional tectonics in Weihe graben. 


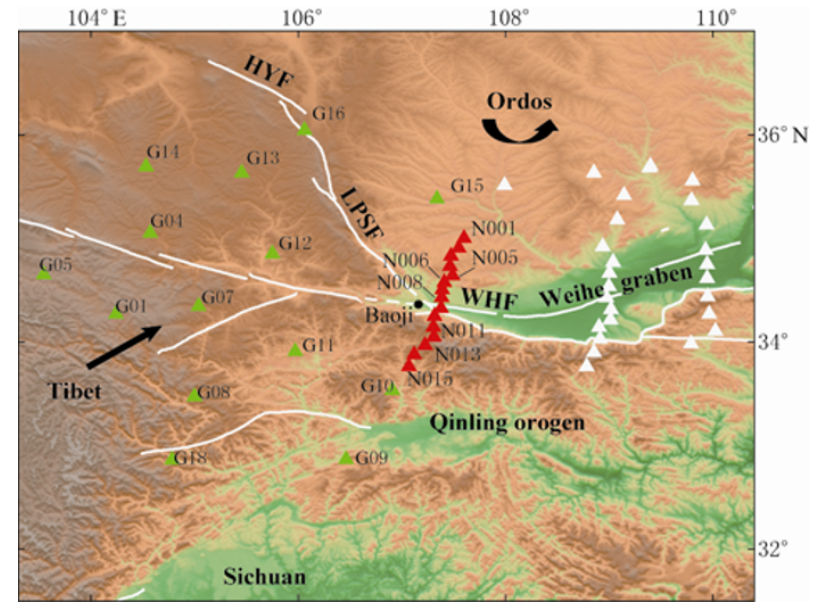

Figure 1 Map of seismic arrays around the Ordos block. The linear NS-trending seismic array consists of 15 stations shown as red triangles near Baoji. Stations from Southwest Ordos Array are shown as green triangles. White triangles are stations from Huang et al. (2008). HYF: Haiyuan fault; LPSF: Liupanshan fracture zone; WHF: Weihe fault.

\section{Data and method}

Peking University deployed a linear array of 15 portable broadband seismometers (Figure 1, shown as red triangles) across the western part of the Weihe graben from September 2005 to August 2006. Each station was equipped with a Guralp CMG-3ESP seismometer and a Reftek 130 digital acquisition system (DAS). Afterwards Peking University also deployed a 2-D seismic array (named Southwest Ordos Array) using 14 STS2 sensors at the southwestern margin of the Ordos during 2007-2008, shown as green triangles in Figure 1. Station locations are listed in Table 1.

We performed shear-wave splitting analyses of both SKS and SKKS phases to estimate the seismic anisotropy in the upper mantle beneath the two arrays. The method by Silver and Chan (1991) was adopted here to determine the splitting parameters, the fast polarization direction $(\phi)$ and the delay time $(\delta t)$, by searching the minimum stacked eigenvalue of the covariance matrix of the two horizontal components for all the SKS/SKKS phases.

Figure 2 shows the way to obtain the splitting parameters using four events at station N008 (Figure 1). In total 54 teleseismic events with epicentral distances between 85 degrees to 150 degrees and $M_{\mathrm{b}}$ of $\geq 5.5$ were used to get the anisotropy parameters.

Table 1 Shear wave splitting parameters at the seismic stations

\begin{tabular}{|c|c|c|c|c|c|c|c|c|c|c|c|}
\hline Station & Lat. $/{ }^{\circ} \mathrm{N}$ & Long. $/{ }^{\circ} \mathrm{E}$ & $\phi /^{\circ}$ & $\delta t / \mathrm{s}$ & $N$ & Station & Lat. $/{ }^{\circ} \mathrm{N}$ & Long. $/{ }^{\circ} \mathrm{E}$ & $\phi /^{\circ}$ & $\delta t / \mathrm{s}$ & $N$ \\
\hline N001 & 35.004 & 107.596 & $-71+3.5 /-3.0$ & $1.0+0.14 /-0.12$ & 20 & G01 & 34.272 & 104.242 & $-58+10.3 /-4.8$ & $1.5+0.46 /-0.28$ & 9 \\
\hline N002 & 34.910 & 107.548 & $-52+4.5 /-6.5$ & $1.1+0.07 /-0.08$ & 22 & G04 & 35.055 & 104.570 & $-60+3.1 /-3.6$ & $1.7+0.18 /-0.26$ & 12 \\
\hline N003 & 34.836 & 107.471 & $-52+1.0 /-1.0$ & $1.1+0.06 /-0.06$ & 19 & G05 & 34.652 & 103.542 & $-70+3.6 /-7.3$ & $1.3+0.15 /-0.12$ & 13 \\
\hline N004 & 34.732 & 107.463 & $-64+4.5 /-9.5$ & $0.5+0.15 /-0.12$ & 15 & G07 & 34.348 & 105.038 & $-65+5.6 /-4.8$ & $1.0+0.08 /-0.10$ & 14 \\
\hline N005 & 34.644 & 107.487 & $-64+2.5 /-2.5$ & $1.1+0.10 /-0.09$ & 20 & G08 & 33.476 & 104.997 & $-85+6.5 /-20.0$ & $0.7+0.28 /-0.16$ & 4 \\
\hline N006 & 34.578 & 107.407 & $-61+3.0 /-3.0$ & $0.6+0.10 /-0.10$ & 12 & G09 & 32.870 & 106.458 & $-90+12.0 /-6.0$ & $1.0+0.19 /-0.15$ & 2 \\
\hline N007 & 34.505 & 107.387 & $-68+5.5 /-8.5$ & $1.1+0.20 /-0.24$ & 8 & G10 & 33.536 & 106.906 & $-70+4.9 /-10.7$ & $0.8+0.08 /-0.11$ & 14 \\
\hline N008 & 34.433 & 107.382 & $-80+3.0 /-3.5$ & $1.0+0.05 /-0.06$ & 7 & G11 & 33.911 & 105.968 & $-70+8.4 /-9.7$ & $1.5+0.12 /-0.15$ & 11 \\
\hline N009 & 34.329 & 107.377 & $-76+1.5 /-2.0$ & $1.1+0.02 /-0.04$ & 11 & G12 & 34.853 & 105.749 & $-60+7.8 /-16.2$ & $1.0+0.17 /-0.12$ & 4 \\
\hline N010 & 34.252 & 107.312 & $-79+2.0 /-1.5$ & $1.0+0.08 /-0.05$ & 13 & G13 & 35.636 & 105.452 & $-55+4.5 /-4.7$ & $1.0+0.09 /-0.17$ & 13 \\
\hline N011 & 34.145 & 107.302 & $-81+2.5 /-2.5$ & $0.9+0.06 /-0.06$ & 16 & G14 & 35.695 & 104.531 & $-65+7.2 /-9.8$ & $1.0+0.16 /-0.12$ & 7 \\
\hline N012 & 34.052 & 107.307 & $-74+2.5 /-3.0$ & $0.9+0.06 /-0.06$ & 8 & G15 & 35.383 & 107.336 & $-60+8.3 /-9.6$ & $1.5+0.21 /-0.26$ & 4 \\
\hline N013 & 33.969 & 107.223 & - & - & & G16 & 36.048 & 106.058 & $-34+6.9 /-5.4$ & $1.3+0.10 /-0.12$ & 8 \\
\hline N014 & 33.881 & 107.117 & $-117+12.5 /-8.5$ & $0.4+0.10 /-0.05$ & 6 & G18 & 32.866 & 104.784 & $-70+7.5 /-8.6$ & $1.3+0.09 /-0.15$ & 9 \\
\hline N015 & 33.766 & 107.064 & $-77+9.0 /-26.0$ & $0.4+0.19 /-0.06$ & 8 & & & & & & \\
\hline
\end{tabular}

Note: $\phi$ is fast wave polarization direction, $\delta t$ is delay time between fast and slow waves. The last column $N$ denotes the number of SKS/SKKS phases to estimate the splitting parameters. A short line indicates that there is no reasonable result.

\section{Results}

Well-constrained splitting parameters were obtained at 28 stations in total shown in Figure 3. The station N013 had no reasonable results, which had one horizontal component 10 times bigger than the other. Detailed splitting parameters at each station are listed in Table 1. Although majority of the teleseismic events in this distance range are from the subduction zones in the southwest Pacific, several earthquakes from northwestern America and the South Indian ocean have expanded the azimuthal coverage (Figure 3), which significantly improved the resolution of the shear-wave splitting parameters.

Analyses of shear wave splitting of SKS and SKKS phases at these stations show that the fast directions 

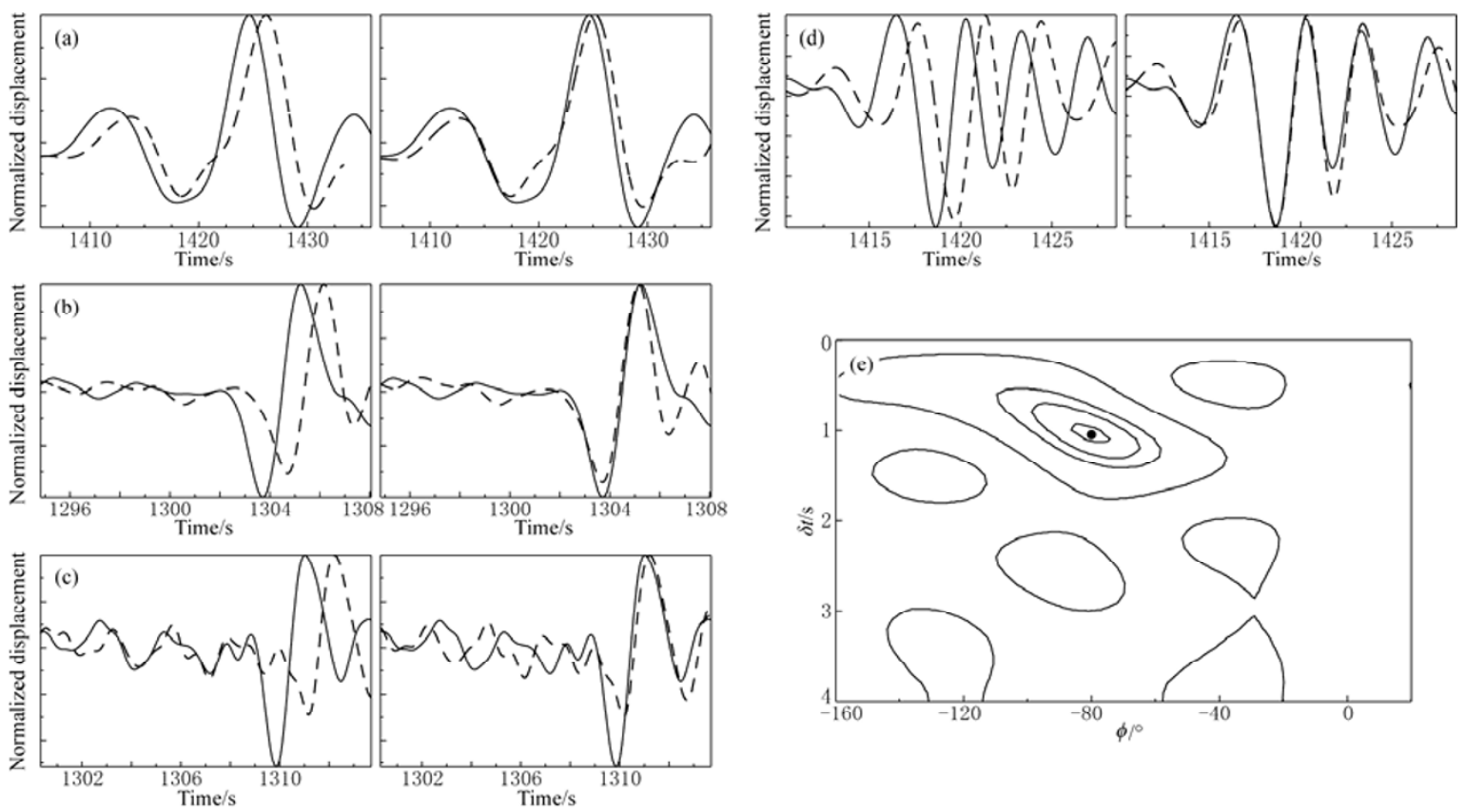

Figure 2 Splitting analysis for the SKS/SKKS phases recorded at station N008 in the center of the 1-D linear seismic array. (a), (b), (c) and (d) are four examples showing superposition of normalized displacement of fast and slow (dashed) components uncorrected (left) and corrected (right). (e) Contour plot for the optimum splitting parameters (black dot) for the four SKS/SKKS phases in the fast direction and delay time space. The smallest contour indicates the $95 \%$ confidence level. The contours are the stacked minimum eigenvalue of the covariance matrix for the four SKS/SKKS phases.
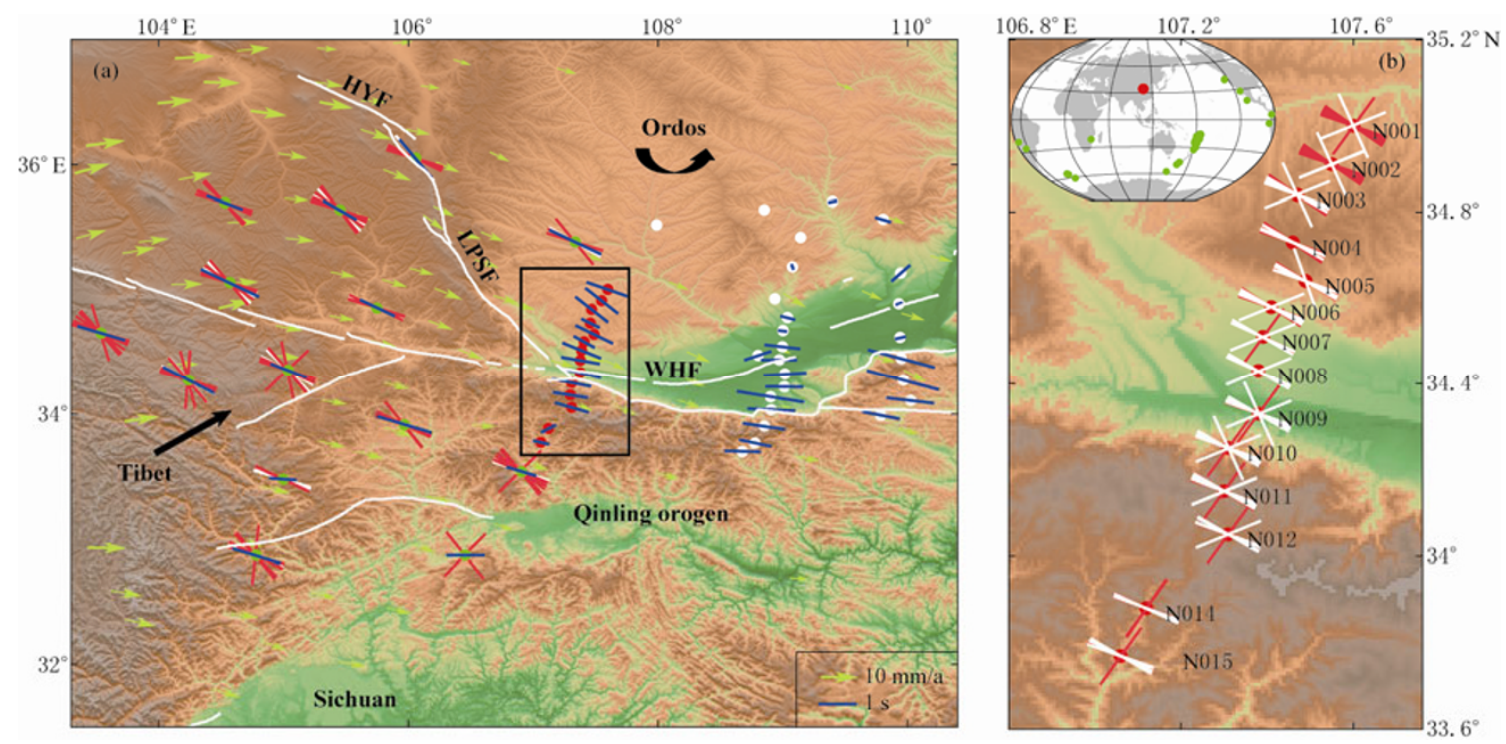

Figure 3 Results of SKS/SKKS splitting analyses. (a) Blue lines are fast polarization directions of shear waves at the stations (shown as red dots) along the linear array and the 2-D Southwest Ordos array (green dots). White dots are the stations from a temporary seismic array by Nanjing University (Huang et al., 2008). Back-azimuth coverage of earthquakes used for SKS/SKKS splitting analyses are also shown as short lines for substantial splitting events (red bars) and null splitting events (white bars). Yellow arrows are the GPS station velocities relative to the stable Eurasian frame (Niu et al., 2005). (b) Back-azimuth coverage of earthquakes used for SKS/SKKS splitting analyses for the N-S array near Baoji. It is clear that the earthquakes with their back-azimuth parallel or perpendicular to the fast polarization direction have null splitting. Inset: distribution of earthquakes (green dots) used for shear wave splitting analysis. The red dot denotes the center of the seismic array. 
generally trend $\sim 110^{\circ}$ with an average delay time of 0.9 $\mathrm{s}$ in the southwestern margin of the Ordos block. Shear-wave splitting results shown in Figure 3 in general have a uniform pattern from the northeast Tibet to southwest Ordos: the fast directions are almost E-W orientation with similar delay times. The fast polarization directions coincide with the orientations of surface geological structures (such as strikes of orogens and faults) and GPS velocity observations at nearby stations on the stable Eurasian reference frame (Niu et al., 2005). These roughly parallel directions in our observed seismic anisotropy and the surface GPS velocity observations indicate a strong coupling between the crust and mantle deformation beneath the study area.

\section{Discussion and conclusions}

Shear wave splitting analysis at our dense seismic array provide us the spatial distribution from northeast Tibet to the southwest boundary of the Ordos block. The integrated splitting results of our analyses and previous studies (Huang et al., 2008) can lead a better knowledge of the material flow driven by the northeast expanding of the Tibetan plateau. First of all, significant and concordant shear wave splittings were obtained across northeast Tibet to southwest Ordos, which may indicate the existence of a thick anisotropy layer.

As field and laboratory studies (Christensen, 1984; Mainprice and Silver, 1993; Zhang and Karato, 1995) show that shear strain associated with material flow preferentially aligns olivine and pyroxene crystals in mantle, seismic anisotropy is usually taken as an indicator of mantle flow. Thus the fast S-wave polarization was usually assumed to primarily reflect the direction of the mantle flow (Savage, 1999). So our shear-wave splitting results can provide seismic evidence for the eastward extrusion of mantle material of the expanding Tibet (Molnar and Tapponnier, 1975; Tapponnier and Molnar, 1977; Zhang et al., 1998; Yin and Harrison, 2000). Large delay times ( $>1$ s) of shear wave splitting in this region suggest that the anisotropy layer in this region would extend to more than $200 \mathrm{~km}$ depth (Silver and Chan, 1988). Our result that the fast directions trend $\sim 110^{\circ}$ is a little different from previous study at the eastern part of Weihe graben (Huang et al., 2008) which demonstrates that the fast directions are of $98.7^{\circ}$. Although there may be uncertainty and manufacture in methodology and data processing, we believe that the rotation of fast directions of shear wave does exist. The direction of material flow has rotates counterclockward from northeast Tibet to eastern part of Weihe graben.

The agreement between the lithosphere deformation (GPS data and Quaternary fault slip rate) and the mantle flow (shear wave splitting) implies similar mantle deformation from lithosphere to asthenosphere has extends to at least $200-\mathrm{km}$ depth at the southwestern boundary of the Ordos block. The collision of Tibet and Ordos had not only resulted in the formation of the Liupanshan mountain thrust belt (Peltzer and Saucier, 1996; Zhang et al., 1998; Li et al., 2005) but also direct the asthenospheric mantle flow along the Qinling-Dabie suture between the Ordos and the Sichuan basin. Although observed seismic anisotropy had also been interpreted as contributions from tectonic fabrics frozen in the lithosphere from deformation in the past, we argue strongly that it is not the case here because of our uniform shear-wave splitting results across the Ordos and the Qinling orogen which belong to different geological units.

The fast $\mathrm{S}$ wave polarizations shown in Figure 3 have a system rotation across northeast Tibet, which are nearly ENE in the south but change gradually to NNE in the north in our study area. This rotation of fast $\mathrm{S}$ wave polarization could be related to the direction of material flow driven by the expanding Tibet. The northeastward extrusion of the Tibetan mantle driven by the continued Indo-Asian continental collision encountered the Ordos block, which is the stable cratonic block with a thick lithospheric root extending to $300 \mathrm{~km}$ depth (Huang and Zhao, 2006). Consequently, we can conclude that the mantle flow is blocked by the Ordos block and restricted in a narrow channel between the stiff Ordos and Sichuan basin (Molnar and Tapponnier, 1975; Tapponnier and Molnar, 1977; Peltzer et al., 1985; Zhang et al., 1998). The counter-clock rotation of the Ordos block (Peltzer and Saucier, 1996; Zhang et al., 1998; Li et al., 2005) and the widening of the Weihe graben toward east have played an important role in accommodating the differential escape between Ordos and the South China block, and the transition from compressional to extensional tectonics driven by the Indo-Asian continental collision.

\section{References}

Chen J H, Liu Q Y, Li S C, Guo B and Lan Y G (2005). Crust and upper mantle S-wave velocity structure across Northeastern Tibetan Plateau and Ordos block. Chinese J Geophys 48(2): 333-342 (in Chinese with English abstract). 
Christensen N I (1984). The magnitude, symmetry and origin of upper mantle anisotropy based on fabric analyses of ultramafic tectonics. Geophys J R astr Soc 76: 89-112.

Huang J L and Zhao D P (2006). High-resolution mantle tomography of China and surrounding regions. J Geophys Res 111: B09305, doi: 10.1029/2005JB004066.

Huang Z X, Xu M J, Wang L S, Mi N, Yu D Y and Li H (2008). Shear wave splitting in the southern margin of the Ordos Block, north China. Geophys Res Lett 35: L19301, doi: 10.1029/2008GL035188.

Li Y X, Zhang J H, Guo L Q, Zhang Z F and Zhang J Q (2005). Counterclockwise rotation and geodynamics of Ordos block. J Geod Geodyn 25(3): 50-56.

Mainprice D and Silver P G (1993). Interpretation of SKS-waves using samples from the subcontinental lithosphere. Phys Earth Planet Inter 78 (3-4): 257-280.

Molnar P and Tapponnier P (1975). Cenozoic tectonics of Asia: Effects of a continental collision. Science 189: 419-426.

Niu Z J, Wang M, Sun H R, Sun J Z, You X Z, Gan W J, Xue G J, Hao J X, Xin S H, Wang Y Q, Wang Y D and Li B (2005). Contemporary velocity field of crustal movement of Chinese mainland from Global Positioning System measurements. Chinese Science Bulletin 50(9): 939-941.

Peltzer G and Saucier F (1996). Present-day kinematics of Asia derived from geologic fault rates. $J$ Geophys Res 101: 27 943-27956.

Peltzer G, Tapponnier P, Zhang Z T and Xu Z Q (1985). Neogene Quaternary faulting in and along the Qinling Shan. Nature 317: 500-505.

Savage M K (1999). Seismic anisotropy and mantle deformation: What have we learned from shear wave splitting? Rev Geophys 37: 65-106.
Silver P G and Chan W W (1988). Implications for continental structure and evolution from seismic anisotropy. Nature 335: 34-39.

Silver P G and Chan W W (1991). Shear-wave splitting and subcontinental mantle deformation. $J$ Geophys Res 96: 16 42916454.

Tang Y C, Feng Y G, Chen Y S, Zhou S Y, Ning J Y, Wei S Q, Li P, Yu C Q, Fan W Y and Wang H Y (2010). Receiver function analysis at Shanxi Rift. Chinese J Geophys 53(9): 2 102-2 109 (in Chinese with English abstract).

Tapponnier P and Molnar P (1977). Active faulting and tectonics in China. $J$ Geophys Res 82(20): 2 905-2 930.

Tong W W, Wang L S, Mi N, Xu M J, Li H, Yu D Y, Li C, Liu S W, Liu M and Sandvol E (2007). Receiver function analysis for seismic structure of the crust and uppermost mantle in the Liupanshan area, China. Science in China (Series D) 50: 227-233.

Yang Z X, Duan Y H, Wang F Y, Zhao J R, Pan S Z and Li L (2009). Tomographic determination of the deep earthquake faults in Yinchuan basin by using three-dimensional seismic transmission technology. Chinese J Geophys 52(8): 2 0262034 (in Chinese with English abstract).

Yin A and Harrison M (2000). Geological evolution of the Himalayan-Tibet orogen. Annu Rev Earth Planet Sci 28: 211-280.

Zhang S Q and Karato S (1995). Lattice preferred orientation of olivine aggregates deformed in simple shear. Nature 375: 774-777.

Zhang Y Q, Mercier J L and Vergely P (1998). Extension in the graben systems around the Ordos (China), and its contribution to the extrusion tectonics of south China with respect to GobiMongolia. Tectonophysics 285: 41-75. 